\title{
Analysis on Evaluation Process of Politics Teachers' Professional Quality
}

\author{
Yexia Sun \\ School of Marxism, Northeast Normal University, People Street No.5268, Nanguan District, \\ Changchun, Jilin Province, China \\ sunyexia@126.com
}

Keywords: Politics teachers; Evaluation; The evaluation stage; Questionnaire analysis

\begin{abstract}
The quality of the politics teachers directly affects the quality of the political class teaching, it becomes a very important issue to evaluate politics teachers. In this paper, with the questionnaire method, for example, it detailed introduces the process of evaluating politics teachers. The evaluation for politics teachers is specifically divided into three stages: preparation stage, evaluation stage and analysis stage. This article will detail the specific process of these three stages and problems to be noticed.

Politics teachers' quality evaluation methods mainly include survey research method, peer review method, benchmarking analysis method and multi-index comprehensive evaluation method. Test method, on-site inspection method, interviewing method, and photographic record are used in the specific implementation, while questionnaire is the most universal and objective evaluation method. Questionnaire has the advantages of wide application, high status and big role in the evaluation. Questionnaire plays a supporting role in social survey, and many social surveys are through questionnaires [1].
\end{abstract}

\section{Preparation Stage}

The implementation of evaluation for this paper revolves around the questionnaire method, and the preparatory stage of the implementation process includes the following steps:

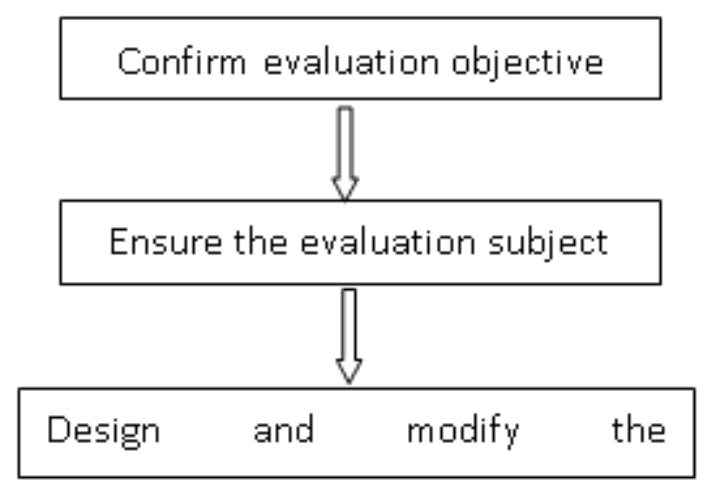

Figure 1. Preparatory stage steps

Confirm Evaluation Objective. The evaluation objective should be first confirmed before the implementation. Politics teachers will be evaluated through practical, scientific and fair evaluation system so as to assess their true level. It will on the one hand help colleges and universities to understand the status of politics teachers' quality, on the other hand will completely feedback the information to teachers who are evaluated, and help them to self-aware, targeted improve themselves and improve their quality. Evaluation has two main goals: First, overall evaluate politics teachers' quality, with more evaluation objects; the second is to evaluate one teacher, with single object [2].

Ensure the Evaluation Subject. The evaluation subject mainly includes experts, peers, self, 
students and the community [3]. Each of the different qualities has its own characteristics, evaluation methods can be designed according to the different qualities' characteristics, and finally become a comprehensive evaluation system. Evaluation methods must be different because of the various qualities, while, regardless of experts evaluation, peers evaluation, self-evaluation, or students evaluation, the most objective one is still quantitative evaluation method. Politics teachers' literacy level can be understood by questionnaire [4].

Design, Modify and Determine the Questionnaire. In designing the questionnaire, the selected portion of the respondents will be in-depth interviewed, and relevant dimensions for measurement and evaluation of politics teachers' quality level will be summarized, and to protocol the survey questions, design questionnaire based on these dimensions. Questionnaire should be regularly designed, and the contents of investigation should be standardized for statistical analysis. Questionnaire generally include: survey title, forewords, explanatory notes, questions, answers and so on. Foreword language should be easy to understand, and the purpose, meaning and content should be explained to the valuators to cause their attention and interest, so that the valuators are willing to accept the investigation. For example, when experts are evaluated the national politics teachers' quality level, the forewords can be written:

\section{Dear experts:}

By the time of the valuable opportunity you participate in on-site meeting, we hope that we can understand some of your views and recommendations on the "politics teachers' quality" issues in order to provide an important basis for us to carry out research in this area, so we carry out the survey for the very purpose. Thank your support for this survey!

When reviewers completing the questionnaire, you may have inconsistent understanding for the filling content and manner with the designer, the explanatory notes are to explain the above content. E.g:

Explanatory notes:

(1) When filling out the questionnaire, tick can be selected on the answer letters, without options, please fill appropriate contents in the blanks.

(2) If you select "Other" option, please make out on the blanks.

After the formation of the first draft of the questionnaire, a questionnaire trial will be conducted, which is an essential step in the design of the questionnaire, and can test and assess questionnaires' quality, checking whether there are more understandings in the questions of the questionnaire, whether answers of the questionnaire are comprehensive and mutually exclusive.

\section{The Evaluation Stage}

After the questionnaire design is complete, then comes the concrete implementation stage of the evaluation system program.

The Number of Questionnaires Is Called the Sample Size in Statistics. Although there is no specific requirement for the sample size, the more the numbers are, the more authentic the survey result is. The numbers needed are a few more for examining the overall level of politics teachers in order to ensure the representativeness of the questionnaire. When evaluating a politics teacher's quality, the respondents are mainly in the universities, so the numbers needed are much smaller, and generic social research sample sizes are between 100 and 2000 [5]. The approximate range of the sample numbers can be confirmed in accordance with the general scale by experience, see Table 1 . However, the overall situation cannot be accurately inferred from the condition of the sample, because such findings can only be reference frame of studying the overall situation. 
Table 1 Empirically determine the range of sample numbers [6]

\begin{tabular}{|l|l|l|l|l|l|l|}
\hline $\begin{array}{l}\text { Politics } \\
\text { Teachers' scale }\end{array}$ & $\begin{array}{l}\text { Fewer } \\
\text { than } \\
100\end{array}$ & $100 \sim 1000$ & $1000 \sim 5000$ & $5000 \sim 10000$ & $\begin{array}{l}10000 \\
100000\end{array}$ & $\begin{array}{l}\text { More than } \\
100000\end{array}$ \\
\hline $\begin{array}{l}\text { Proportion of } \\
\text { samples in the } \\
\text { overall }\end{array}$ & $50 \%$ & $50 \% \sim 20 \%$ & $30 \% \sim 10 \%$ & $15 \% \sim 3 \%$ & $5 \% \sim 1 \%$ & $\begin{array}{l}\text { Fewer } \\
\text { than } 1 \%\end{array}$ \\
\hline
\end{tabular}

Number of questionnaires depends on the number of respondents. There are two cases confirming the respondents: one is that all members within a limited range are evaluation subject; one is to randomly select specific respondent within a certain realm. Since the response rate and effective rate of a questionnaire are not one hundred percent, so specific respondent numbers are greater than predetermined sample numbers, the actual respondents $=$ predetermined sample numbers / (response rate * effective rate), and the lower response rate and effective rate are, the more the actual respondent numbers are [7].

Questionnaire's Distribution. There are many ways for questionnaire's distribution, the most important ones are mail distribution, newspaper distribution, network distribution, delivery distribution and questionnaire interview. Different questionnaire's distribution ways have diverse characteristics, mail distribution, newspaper distribution and network distribution are anonymous, and their evaluation subjects are undisturbed. The questionnaire's questions can be completed according to respondents' own will, but the questionnaire response rate and effective rate are relatively low. Based on practical experience, we generally know that the final response rate of newspaper questionnaire is generally $10 \%$ to $20 \%$, mail distribution response rate is generally $30 \%$ to $60 \%$, and the fluctuation of network distribution response rate is relatively large. The respondents can direct contact with the evaluation subjects in delivery distribution and questionnaire interview, the questions evaluation subjects do not understand can be directly asked for the investigators. The effectiveness and recovery of the questionnaire is much higher, and delivery distribution reply rate is generally $80 \%$ to $90 \%$ [8], while questionnaire interview recovery rate can generally able to achieve one hundred percent. However, investigators on the spot may affect the evaluation subjects to answer questions, thereby affecting the quality of the survey. Investigators ascertain the questionnaire's distribution way according to investigation's requirements and specific circumstances of reality.

Sort out Questionnaires. After distributing the questionnaires, the main task of the investigators is to sort out questionnaires. Questionnaire recycling generally have four cases: questionnaires distributed by mail and questionnaires distributed by newspaper are returned from the evaluation subjects by post office; questionnaires distributed by delivery are retrieved by investigators; network distribution questionnaires are sent back through the network; questionnaire interview are brought back by the investigators themselves. Investigators will generally indicate the date or deadline on the questionnaire. After the questionnaires are collected, to review questionnaires, exclude invalid questionnaires; sort and count the questionnaires, then calculate the questionnaire response rate and effective rate; have certain forms of processing on questionnaires, fill out with clearly writing, polish the missing word, repair damaged questionnaires, and too much loss of contents are regarded as invalid questionnaire.

The Analysis Stage. In the analysis stage, appropriate statistical analysis methods are used to collect large amounts of data, which will be aggregated, understood and digested, and then can play a role of data. Data analysis is to extract useful information and form conclusions, and then to detailed study and summarize the data [9].

First, the questionnaire code will be classified and reorganized into information systems according to the content of raw data. After questionnaire's conversion processing, specific answers have been converted into 10 Arabic numerical codes of 0-9, and the next task is to input these numerical codes to a computer in preparation for statistical analysis. To reduce the error rate of data, data also should be cleaned up by the computer. For any variable on a questionnaire, its efficient 
coding value has a range. When the data in a digital are over-range, it will be sure that this number must be wrong. Logical consistency is slightly more complicated, it can be used to check reasonableness of anteroposterior data according to the questionnaire's problems that mutual exist in inherent logic connection. For example the question: "As a politics teacher, whether you publish this subject-related papers every year?" the answer is no. The next question: "What's the number you annually publish papers related to this subject?" If the answer is more than 1, the data are certainly wrong. When the answer is within the scope and no logical error, then there may be data errors, at that time, random sampling method should be used to estimate and evaluate the whole data quality with a portion of the checking results of the samples. $2 \%$ to $5 \%$ of the samples can be extracted for proofreading.

The intended purpose of the evaluation generally includes selection, identification, recognition, diagnosis, improvement and objective criteria achievement's judgment. For the quality evaluation of ideological and political theory class teachers, the most fundamental purpose is to observe whether the evaluation result is truly, comprehensively and objectively reflects the level of quality, and whether to promote the development of teachers. Through the diagnostic analysis on evaluation, it is not only to be found the problems exist in the quality of teachers and the reasons of the problems, but also to be proposed solutions of the problems. Meanwhile, the analysis of advantage of teachers' development can also play a role to guide and inspire them. In short, politics teachers' quality evaluation system as the core, in the application of operational teacher evaluation programs, teachers' self diagnosis and self reflection should be emphasized, to listen to the views of the multiparty evaluation, to obtain self-improvement information from multiple channels, which is an important method to constantly improve the quality of politics teachers [10].

\section{References}

[1] Wang Jing, University Teacher Evaluation Research Overview, The Sscience Education Article Collects, (2015) No. 3.

[2] Ma Zhonghong, Several Roles Ideological and Political Lesson Teachers Should Play, Ideological and Political Education, (2013) No. 1.

[3] Liao Ke, Reflections on the Evaluation Criteria for University Teachers, Teaching (Higher Education Forum), (2016) No. 7.

[4] Nan Jiwen, The Status, Problems and Upgrading Strategy of Teachers' Assessment Attainment, Teacher Education Forum, (2016) p.6.

[5] Zhao Jun, Implementation Strategies of Teachers' Evaluation Mechanism in China, Education in Asia and the Pacific, (2015) No. 10.

[6] Yuan Fang, social investigation Principles and Methods, Higher Education Press, (1990)

[7] Qiu Qiang, University Faculty Evaluation System Optimization Research, Education Review, (2015) No.8.

[8] Xie Jungui, Social Research Method, Beijing Institute of Technology Press, (2009) p.158.

[9] Yang Li, Ideological and Political Classroom Teaching Behaviors Research, Teaching and Management, (2013) No. 11.

[10] Yan Pingchang, The Actual Challenges and Strategies for Politics Teachers' Quality under the New Situation, Higher Education Forum, (2010) No. 10. 